\title{
On-Campus Study: An experienced overview and preference of undergraduate students in the UAE
}

\begin{abstract}
The study is an attempt to enquire into the preference of undergraduate students, after a considerable and over a year-long experience with Online Teaching and Learning (OTL), under the emergency preventive measure of switching from the traditional face-to-face classes to online. The study followed an exploratory approach, with a quantitative survey followed by a qualitative one, and a convenient sampling method to collect responses from a substantial sample size.

The study is positioned after more than a year of remote classes by the undergraduate student, and hence represents highly experienced reflections and preferences from these students, as compared to other studies conducted last year.

The study has profound implications in considering, and questioning, the importance of on-campus classes, and significance of the physical presence of a tutor in the class, and its effect on the learning experience of undergraduate students.
\end{abstract}

Iftikhar A Khan', M Nawaz Brohi' ${ }^{2}$, Arooj Baig ${ }^{3}$, Abdul Basit ${ }^{4}$

$\mathbf{1 , 2 , 3 , 4}$ Department of Creative Computing

Bath Spa University RAK, UAE

1iftikhar@bathspa.ae

2mnbrohi@bathspa.ae

3arooj@bathspa.ae

4abdul@bathspa.ae

Keywords: COVID-19, online teaching and learning, face-to-face, learning management system

Corresponding author: ${ }^{2} \mathrm{M}$ Nawaz Brohi, Department of Creative Computing, Bath Spa University, Ras Al Khaimah, United Arab Emirates. 


\section{Introduction}

It has been a devastating year since the first cases of COVID-19 were identified in December 2019, and the virus continues to haunt the world with over 160 million cases and 3.3 million deaths (www.arcgis.com) worldwide as of 12 May 2021. While several vaccines, developed in an unprecedented time frame, continue to be administered across the globe, new mutated variants of the virus are the latest threat and challenge, unleashing havoc in few countries such as India.

The United Arab Emirates announced its first case of COVID-19 on 29th January 2020, and after a few initial precautionary measures, such as canceling all extracurricular events and closing universities for four weeks initially, the UAE's Ministry of Education finally directed all universities in mid of March 2020 to switch to Online Teaching and Learning; and so they have been ever since. Fortunately, UAE has one of the highest penetration (98\%) of high-quality internet connection (ITU, 2018), that fundamentally and effectively supported the institutions, tutors, and students to quickly and conveniently switch from the traditional on-campus Face-to-Face (FTF) model, use online video meeting tools, and manage regular and uninterrupted synchronous lectures. From March 2020 to April 2021, it has been more than a year of complete and continued remote learning for university students. While initially challenging, it is commendable how both students and tutors have stayed resilient to make the most out of the situation and continue to progress with academic progress (Juliani, 2020).

The OTL was, and continues to be, a joint effort and success of four of the following stakeholders who had to step up to the occasion and make a relevant, significant, and critical contribution to the process and experience:

\section{The Institutions}

- Quickly try, purchase and deploy a robust and dependable online meeting platform for the students and tutors.

- Provide technical training and assistance to tutors and students to get to understand and use the selected platform effectively and responsibly.

- Establish and inform all tutors, students, and parents to follow online protocol for an effective, efficient, and safe learning experience.

\section{Tutors}

- Publish and make sure all teaching and assessment material is conveniently available online, such as on a Learning Management System (LMS).

- Create bulk calendar events and links for each of their teaching sessions.

- Start the online teaching session before time, preferably with the video on.

- Conduct the session, sharing screens for lecture presentations and other teaching aids.

- Record attendance.

\section{Students}

- Join the teaching sessions before time.

- Keeping the mics off throughout the sessions, unless excusing for a question, or responding to the tutor's question.

- Freedom to keep the video on or off, as deem appropriate. 


\section{Parents}

- Provide and prepare a designated area for regular and formal classes at home.

- Provide and monitor the minimum requirements such as a computer/laptop, camera/mic, and a stable internet connection.

- Adjust home routines to adequately support online classes at home with minimum distractions and disturbance.

While several studies (Li \& Akins, 2005; Conrad, 2004; Redmond, 2011; McQuiggan, 2012) have indicated that neither of the FTF classes and OTL is easier or more challenging than the other, and Li et al. (2018) have argued that students may establish and thrive as good interpersonal relations with OTL just as in FTF classes; this research is an exploratory study with a mixed approach, to further re-examine and re-investigate into the experience of the undergraduate students with the recent year-long OTL, review their perspective and identify their preference.

\section{Related Work and Literature Review}

The entire year of online teaching and learning was underlined with varying levels of stress, anxiety, and confusion, with several factors such as serious health and life hazard, financial and career losses, limited access to technology in developing countries, with the pandemic showing little signs of slowing down (Boa, 2020). Several studies have documented losing motivation and focus amidst a pandemic (Hasan \& Bao, 2020). In fact, there's a big question mark on when this crisis will be over, and when and how things will return to normal like they were at the end of 2019 (Lee et al., 2020).

While Vu \& Fadde (2013) have pointed that online teaching develops feelings of isolation amongst students with no real interactions with peers, and Mawn et al. (2011) have highlighted how online teaching is typically limited with practical studio or lab-based courses; Richardson et al. (2015) have raised concern on the limited presence, influence, and engagement of the tutors in the online classes. Gray \& DiLoreto (2016) say that the individual personalities of the students are a strong predictor of their performance and satisfaction with online learning.

Ghazi et al. (2020), in their multiple case study with undergraduate students, found a strong appreciation and longing by the students, for real and personal interaction between students and tutors, and among students themselves. This was despite a clear agreement by the majority of the students that the online teaching was well transitioned from the regular one, was well organized, supporting, and effective.

Cauchemez et al., $(2008,2009)$ documented and quantified the role of closing schools for students under a pandemic crisis in France. In their study, they found that closing schools and seizing the contact between students can decrease the number of cases by 13-17 percent, and could go up to $40 \%$ at the height of the pandemic. Earn (2012) too found in his study on the h1n1 influenza pandemic in Canada in 2009 , that the school closed in time could have limited the spread of the infection in school-going children by as much as $50 \%$.

Hodges et al., (2020) have cautioned the academic community not to confuse online or virtual learning with the current temporary remote online delivery, and management of lessons and assessments, under a dire global pandemic emergency; terming it as the "emergency remote learning" (ERL). Like in Afghanistan, where radio and DVDs were used to continue academic progress in the face of continued violence (Davies \& Bentrovato, 2011); and Palestine, where a web-based interactive program was developed (Shraim \& Khlaif, 2010) to counter frequent closing of schools. They explain how online or 
virtual teaching has an entirely different model, approach, and preparation; whereas all the traditional institutions and students right now are just trying to survive the academic progress, make the most of it, and will ultimately return to the traditional setup, as soon as the crisis is contained. Though they also strongly recommend reviewing, reflecting, and learning from this unique long experience, and exploring efficient and effective technical possibilities for the future.

Rahiem (2020) in her study with undergraduate students in Jakarta found a paradox in students' experience with emergency remote learning, where while they liked staying and studying from home, they also reported several challenges such as confusion, depression, and isolation. Bao (2020) highlights the need for timely and adequate psychological counseling to the students, to relieve their anxiety, and to improve concentration and engagement in online classes. Reich et al. (2020) have highlighted a few limitations of remote learning such as lack of eye contact and gestures, as well as inappropriateness of home as a space to study effectively; while also identifying few advantages of online learning such as availability of recorded lectures, encouragement of self-directed learning, and tutors learning new skills and technology,

In a study with 133 undergraduate and graduate students at the University of Dubai, Nasser (2020) found that $46 \%$ of the students found online teaching effective, whereas $24 \%$ did not. While $57 \%$ of the students expressed concern over very limited collaboration amongst themselves, $55 \%$ of the students liked the online classes. Finally, concluding that while $49 \%$ of students recommended a blend of oncampus and online classes, $26 \%$ preferred fully online and only $25 \%$ preferred traditional on-campus learning; Nasser goes on to recommend universities in the UAE to deliver to the students' demand and switch from traditional to blend mode of teaching.

\section{Material and Methods \\ 3.1 Research Design}

The study undertook a mixed approach undertaking both quantitative and qualitative research over a period of 3 months. Initially, a short quantitative survey was conducted, for which 137 responses were recorded. After a settling period of over a month, an open-ended qualitative survey was issued to the same participants that recorded 12 responses. The qualitative survey followed the quantitative to crossexamine initial trends and results.

\subsection{Participants and Data}

Following a convenient sampling method, the study was planned and conducted with the undergraduate students of a British university operating in the UAE. Both the surveys were prepared on Google Forms and forwarded to students through the university's official social media channel. 
Table 3.1 Summary of the respondents

\begin{tabular}{|c|c|c|}
\hline Response Summary & Count $\mid 137$ & Percentage \\
\hline \multicolumn{3}{|l|}{ Gender } \\
\hline Male & 75 & 57.3 \\
\hline Female & 54 & 41.2 \\
\hline Other & 2 & 1.5 \\
\hline \multicolumn{3}{|l|}{ Nationality } \\
\hline Philipino & 98 & 73.1 \\
\hline Pakistani & 25 & 20.9 \\
\hline Other & 8 & 6 \\
\hline
\end{tabular}

Table 3.2 The esponses for the short quantitative survey

\begin{tabular}{|c|c|}
\hline Survey queries & Responses \\
\hline I think remote teaching \& learning & $\%$ \\
\hline is not as effective as on-campus physical classes & 55.1 \\
\hline is as good as on-campus physical classes & 33.8 \\
\hline is working better than on-campus physical classes & 11.1 \\
\hline My biggest challenge with remote learning was & $\%$ \\
\hline following \& understanding the lectures & 23.4 \\
\hline technical problem & 22.6 \\
\hline concentration & 16.1 \\
\hline self-discipline & 12.4 \\
\hline
\end{tabular}




\begin{tabular}{|c|c|}
\hline motivation & 11.7 \\
\hline communication with tutors & 8.0 \\
\hline communication with peers & 5.8 \\
\hline I felt lost most of the time during remote learning & $\%$ \\
\hline Neutral & 43.1 \\
\hline Agree & 40.2 \\
\hline Disagree & 16.8 \\
\hline The true value of regular on-campus classes lies in & $\%$ \\
\hline physically interacting \& engaging with tutors & 62.0 \\
\hline working \& learning with competent students in the class & 23.4 \\
\hline discipline in class timings \& examinations & 8.0 \\
\hline accredited degree qualifications & 5.8 \\
\hline In my experience, I learn \& work best with & $\%$ \\
\hline On-campus face-to-face classes & 67.9 \\
\hline remote learning & 32.1 \\
\hline I can't wait to resume my regular on-campus classes & $\%$ \\
\hline Agree & 58.8 \\
\hline Neutral & 33.8 \\
\hline Disagree & 7.4 \\
\hline
\end{tabular}


Table 3.3 The most prominent comments from the open-ended qualitative survey

\begin{tabular}{l}
$\begin{array}{l}\text { "On-campus learning allows a much better interaction between us students, and our teachers, which } \\
\text { increases the efficiency and potency of our learning." }\end{array}$ \\
\hline "Face to face classes make students pay proper attention towards the tutor." \\
\hline $\begin{array}{l}\text { "Remote learning allows for students to remain home and be able to learn and study at their own pace, } \\
\text { removing the problem of hectic preparation in the morning to wait for the bus." }\end{array}$ \\
$\begin{array}{l}\text { "Remote classes are less engaging, and physical activities (like most group activities) are impossible } \\
\text { or clunky when converted to online format" }\end{array}$ \\
\hline "Online classes allow too much freedom, students may slack off and that can also affect group work." \\
\hline $\begin{array}{l}\text { "On campus learning, learning face to face is more fun. That's the way of learning we people grew up } \\
\text { with, so we are more capable of learning face to face rather than in online class." }\end{array}$ \\
\hline $\begin{array}{l}\text { "On-campus learning allows both student and teacher to perform hands-on learning, and better } \\
\text { communication on-site with the teacher." }\end{array}$
\end{tabular}

\section{Discussion and Results}

It has been a challenging, demanding, and evolutionary year in every aspect of life ever since the COVID-19 pandemic gripped the entire world in March of 2020. This study was an attempt to investigate the preference of university students with the OTL, as an emergency measure to substitute the traditional on-campus FTF classes. To begin with, a good majority of these UG students $(55.1 \%)$ clearly regarded the OTL as not being as effective as on-campus FTF classes. This correlates well with another figure where $40.2 \%$ of them have confessed to feeling lost during remote sessions, which would have affected the comprehension of lectures, and subsequent effectiveness of OTL. This correlation can be attributed to the difference between the presence and absence of a structured and disciplined schedule, formal physical class environment, and physical presence of tutor and peers, which can be the key motivation, pressure, or instigation to pay attention, engage, and respond to lectures, discussions, and activities; and ultimately affecting the quality of teaching and learning. One student has shared in the qualitative survey, how physical classes support them to focus and pay attention to tutor and lecture. However, it is also worth noticing how $33.8 \%$ of the students found the OTL to be as effective as FTF classes, whereas $11.1 \%$ regarded it working even better than FTF. This is very interesting too, in the light of the studies (Li \& Akins, 2005; Conrad, 2004; Redmond, 2011; McQuiggan, 2012) which have compared and equated the efficiency and effectiveness of OTL with that of FTF classes; as overall, a very substantial $44.9 \%$ of students have regarded OTL as either as good or better than FTF classes. It is worth mentioning here how this figure coordinates well with the findings of Nasser (2020) where 46\% of the students found OTL as effective.

The study found that the biggest (23.4\%) challenge the university students faced with OTL was difficulties with following and understanding the lectures. This can be attributed to the finding of (Hasan \& Bao, 2020) where they indicated a lack of motivation and focus in students when studying online. Interestingly, only $8 \%$ of students pointed to struggling with communicating with tutors during this period of online engagement. While it is very reassuring to note that there was a very little struggle or challenge with communicating with tutors, the struggle to follow and comprehend indeed appears to be contributed to a lack of motivation and focus. Also, it is worth noting how the second biggest struggle 
was attributed to technical issues. These would include access to the connection speed, system requirements, and availability of a camera or mic. As Hodges et al., (2020) strongly emphasized recognizing online teaching and learning since last year, as an Emergency Remote Teaching (ORT), it is understandable how, when everyone from institutions, tutors, students, and parents have been through a sudden switch from regular on-campus to online, students would have faced technical limitations and issues, especially during the initial transfer phase. It is also worth noting how several well established online meeting platforms such as Zoom, Microsoft Teams, and Google Meets too were not ready for online classes with tens of students with appropriate protocols, and have shown considerable evolution over the last year responding to the issues of screen sharing, attendance, archive, security and file sharing.

Despite $44.9 \%$ of the students finding the OTL to be either as or more effective than the FTF classes, a strong $62 \%$ of them have expressed their appreciation and regards for the physical presence of tutors in the class, which correlates well with the $55.1 \%$ of students not happy with the OTL. This also coordinated with many comments in the qualitative survey, where several respondents highlighted the importance and effectiveness of being physically in class with tutors and peers, for a more engaging and effective learning experience.

Also, when asked what works best for their learning between the OTL and on-campus FTF classes, a substantial majority of $67.9 \%$ of the students expressed they learn best with the FTF classes. This is both substantial, as it is almost three-fourth of the sample size; as well as significant, as they have opted for FTF classes in the future after more than a year of considerable experience with the OTL; though it contradicts the findings of Nasser (2020) who found only $25 \%$ of the students voting to return to traditional FTF classes. This disparity in satisfaction and preference deserves a deeper investigation to the students' attitude (gray) and also the subjects of study (mawn), as both are strong factors that determine the success and failure of OTL. Finally, another good majority of $58.8 \%$ of the students expressed how they could not wait to return back to their on-campus classes, with their tutors and peers.

\section{Conclusions}

Deploying both a quantitative as well as a qualitative survey, the study was a substantial attempt to gauge university students' preferred mode of study, after a substantial experience in both physical and online classes. The study can safely conclude that a majority of the university students appreciate and value the importance of disciplined on-campus FTF classes, and most importantly, the physical presence of, and engagement with, their tutors. They recognize and look forward to, the learning experience with the physical presence of a tutor in a class and their peers. The study draws from the data that even as a good majority of students found the OTL effective, yet a much bigger majority will prefer, and cannot wait, to return to the on-campus classes. The study also recommends against a complete switch from traditional FTF classes to fully OTL, but does recognize and recommends first investigating into the achievements and advantages of OTL, and then consider gradually evolving the FTF classes with adequate and appropriate incorporation of limited and meaningful OTL experience for the students.

\section{Future Work and Recommendations}

A couple of limitations with the study was it being limited to just one university in the UAE, and also with one particular nationality in a very big majority. It would be very useful to run the same study with several universities across a few countries to draw conclusive and more detailed insights and conclusions on the learning preference of university students. 


\section{References}

1. Ministry of Education 2020, United Arab Emirates, accessed 20 July 2020, $<$ https://www.moe.gov.ae/En/OpenData/pages/home.aspx $>$

2. Juliani, A. J. (2020). THIS IS NOT ONLINE OR DISTANCE LEARNING. Retrieved from http://ajjuliani.com/this-is-not-online-or-distance-learning/

3. Li, Q., \& Akins, M. (2005). Sixteen myths about online teaching and learning in higher education: Don't believe everything you hear. TechTrends, 49(4), 51-60.

4. Conrad, D. (2004). University instructors' reflections on their first online teaching experiences. Journal of Asynchronous Learning Networks, 8(2), 31-44.

5. Redmond, P. (2011). From face-to-face teaching to online teaching: Pedagogical transitions. In Proceedings ASCILITE 2011: 28th Annual Conference of the Australasian Society for Computers in Learning in Tertiary Education: Changing Demands, Changing Directions (pp. 1050-1060). Australasian Society for Computers in Learning in Tertiary Education (ASCILITE).

6. McQuiggan, C. A. (2012). Faculty development for online teaching as a catalyst for change. Journal of Asynchronous Learning Networks, 16(2), 27-61.

7. Bao, W. (2020). COVID-19 and online teaching in higher education: A case study of Peking University. Human Behavior and Emerging Technologies, 2(2), 113-115.

8. Lee, S. A., Mathis, A. A., Jobe, M. C., \& Pappalardo, E. A. (2020). Clinically significant fear and anxiety of COVID-19: A psychometric examination of the Coronavirus Anxiety Scale. Psychiatry Research, 290(2020), 1-7, 113112. https://doi.org/10.1016/j.psychres.2020.113112

9. Hasan, N., \& Bao, Y. (2020). Impact of "e-Learning Crack-up" perception on psychological distress among college students during COVID-19 pandemic: A mediating role of "Fear of Academic Year Loss". Children and Youth Services Review, 118(2020), 1-9, 105355. https://doi.org/10.1016/j.childyouth.2020.105355

10. Vu, P., \& Fadde, P. J. (2013). When to talk, when to chat: Student interactions in live virtual classrooms. Journal of Interactive Online Learning, 12(2), 41-52.

11. Mawn, M. V., Carrico, P., Charuk, K., Stote, K. S., \& Lawrence, B. (2011). Hands- on and online: scientific explorations through distance learning. Open Learning: The Journal of Open, Distance and eLearning, 26(2), 135-146.

12. Richardson, J. C., Koehler, A. A., Besser, E. D., Caskurlu, S., Lim, J., \& Mueller, C. M. (2015). Conceptualizing and investigating instructor presence in online learning environments. The International Review of Research in Open and Distributed Learning, 16(3), 256-297.

13. Gray, J. A., \& Diloreto, M. (2016). The effects of student engagement, student satisfaction, and perceived learning in online learning environments. NCPEA International Journal of Educational Leadership Preparation, 11(1). Retrieved from: https://files.eric.ed.gov/fulltext/EJ1103654.pdf

14. Ghazi Saidi, L., \& Vu, Ph., (submitted), Factors that Make Academic Professors Excellent Teachers: A Students' Perspective, Teaching in Higher Education: Critical Perspectives

15. Cauchemez, S., Ferguson, N. M., Wachtel, C., Tegnell, A., Saour, G., Duncan, B., \& Nicoll, A. (2009). Closure of schools during an influenza pandemic. The Lancet Infectious Diseases, 9(8), 4732481. https://doi.org/10.1016/S1473-3099(09)70176-8

16. Cauchemez, S., Valleron, A.-J., Boëlle, P.-Y., Flahault, A., \& Ferguson, N. M. (2008).

17. Estimating the impact of school closure on influenza transmission from Sentinel data. Nature, 452(7188), 7502754. https://doi.org/10.1038/nature06732

18. Earn, D. J. D. (2012). Effects of School Closure on Incidence of Pandemic Influenza in Alberta, Canada. Annals of Internal Medicine, 156(3), 173. https://doi.org/10.7326/0003-4819-156-3-201202070-00005

19. Hodges, C., Moore, S., Lockee, B., Trust, T., \& Bond, A. (2020). The Difference Between Emergency Remote Teaching and Online Learning. Educause Review.

20. Davies L, Bentrovato D (2011) Understanding education's role in fragility: synthesis of four situational analyses of education and fragility: Afghanistan, Bosnia and Herzegovina, Cambodia, Liberia. 2011, IIEP research papers. International Institute for Educational Planning, Paris 
21. Shraim K, Khlaif Z (2010) An e-learning approach to secondary education in Palestine: opportunities and challenges. Inf Technol Dev 16(3):159-173

22. Rahiem, Maila. (2020). The Emergency Remote Learning Experience of University Students in Indonesia amidst the COVID-19 Crisis. International Journal of Learning, Teaching and Educational Research. 19. 1-26. 10.26803/ijlter.19.6.1.

23. Reich $\mathrm{J}$ et al (2020) Remote learning guidance from state education agencies during the Covid-19 pandemic: a first look. EdAr-Xiv 2020. https://doi.org/10.35542/osf.io/437e2

24. Nasser A. Saif Almuraqab. (2020) Shall Universities at the UAE Continue Distance Learning After the COVID-19 Pandemic? Revealing Students' Perspective, International Journal of Advanced Research in Engineering and Technology 